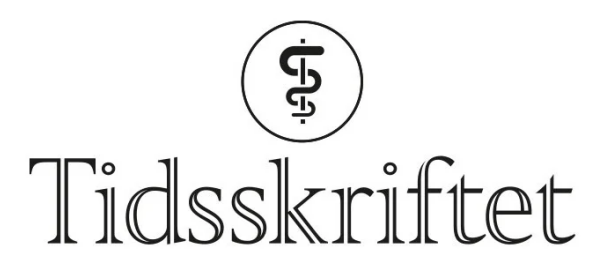

DEN NORSKE LEGEFORENING

\title{
Tanker om sjanker og gleden med syfilis
}

INTERVJU

Det er først når sjanker blir et samtaletema, at Ellen Støkken Dahl blir til et stort smil. Halvparten av forfatterparet bak suksessen Gleden med skjeden har nemlig et helt spesielt forhold til syfilis.

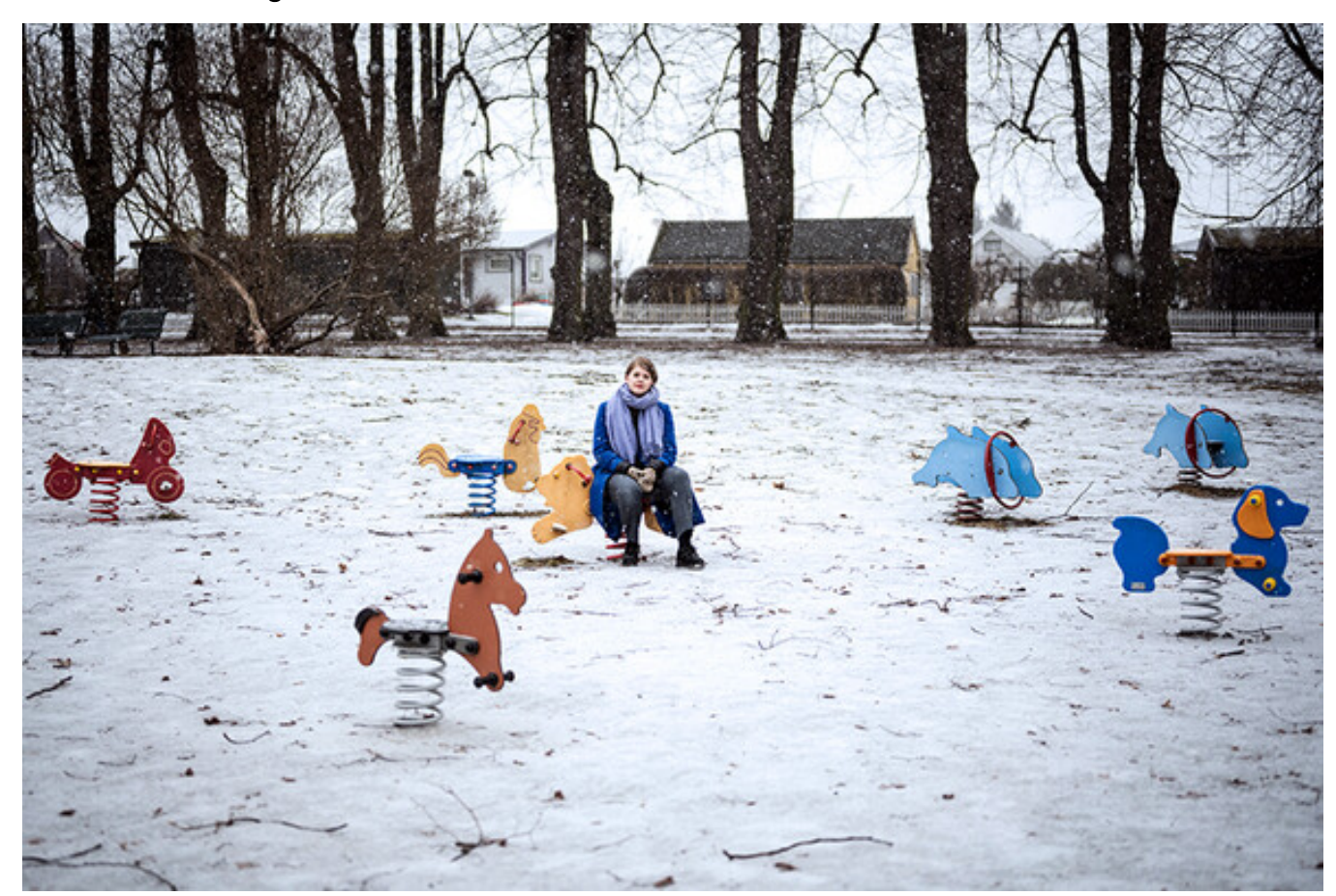

Foto: John Trygve Tollefsen

«Blant medisinere er syfilis kjent som 'den store imitator', men etter mange år som medisinerstudent har jeg møtt på flere sykdommer som slåss om å få bære det navnet», skriver Ellen Støkken Dahl i en artikkel om syfilis i antologien Blod og bein som kom i 2019. Siden er hun blitt ferdig lege og er for tiden i turnus på Bærum sykehus. Mest kjent er hun likevel for den internasjonale bestselgeren Gleden med skjeden, som hun ga ut med kollega 
Nina Brochmann i 2017. Boka er solgt i mer enn en halv million eksemplarer, fulgt opp av nye boksuksesser om puberteten som Jenteboka, og nå sist Gutteboka. Interessen for underliv startet derimot hos de to legeforfatterne lenge før bokutgivelser.

\section{Skorpedannende sår}

Det er kaldt ute, men varmt inne i den lille lune leiligheten på Bjølsen når Tidsskriftet kommer på besøk. Kledd i en rosa skjorte og løse bukser er det en alvorlig, men vennlig Ellen Støkken Dahl som tar oss imot. Hun byr på en kopp te og ber oss velge fra et uvanlig velassortert utvalg. En vakker tekanne i støpejern fylles opp før vi setter oss på hver vår side av et bord med våtservietter og babyutstyr.

- Beklager rotet. Vi bruker foreløpig dette bordet som stellebord, forklarer Støkken Dahl som også er nybakt mor.

Hun rydder litt unna så tekannen får plass. Men til saken:

- Hva sier du hvis jeg sier bløt sjanker?

Og det er her Ellen Støkken Dahl smiler for første gang:

- Da sier jeg sjankroid eller ulcus molle, og ikke syfilis, understreker trettiåringen og fortsetter engasjert:

- På 18oo-tallet kjente man ikke til distinksjonen mellom hard sjanker som man får av syfilis, og bløt sjanker som man får av ulcus molle. På midten av 18oo-tallet endte lege og professor ved «hudsygeavdelingen» i Christiania Carl Wilhelm Boeck opp med å smitte pasienter med ulcus molle når han prøvde å behandle syfilis, forteller Støkken Dahl entusiastisk.

- Og det var jo litt dumt, legger hun tørt til.

\section{Ellen Støkken Dahl}

Forfatter, lege og foredragsholder

Født 1991, fra Stavanger. Bor i Oslo

Cand.med. ved Universitetet i Oslo i 2010-18

Lege ved Sex og samfunn 2018-20

Turnuslege på Bærum sykehus fra september 2020

Medforfatter av Gleden med skjeden (2017), Jenteboka (2019), Blod og bein (2019) og Gutteboka (2021)

Holdt i 2017 TEDx-foredraget «The Virginity Fraud» om mytene om jomfruhinnen med Nina Brochmann. Foredraget er sett over 15 millioner ganger

Gikk på Aschehougs skjønnlitterære forfatterskole i 2017

Historien om Boecks uheldige medisinske eksperimenter kommer vi tilbake til, men la oss først friske opp begrepet sjanker (for de av oss som måtte ha glemt det). Vi snakker om sår, ofte på kjønnsorganer, forårsaket av enten bakterien Haemophilus ducreyi eller spiroketen Treponema pallidum, selveste syfilis-mikroben. Entusiasmen for nevnte sykdom har blant annet gjort at hun som nybakt mor og turnuslege i tillegg skriver på en ny bok. Denne gangen om kjønnssykdommer og kjønnssykdommenes historie. 


\section{Monologer om skjedekrans}

- Før jeg valgte å bli lege hadde jeg et ønske om å bli forfatter, forklarer Støkken Dahl.

- Mange blir jo lege fordi man er flink og ofte pliktoppfyllende.

- Er du pliktoppfyllende?

- Jeg passet inn i klisjéen om den skoleflinke og var glad i å lære om hvordan ting hang sammen. Jeg har blitt mindre pliktoppfyllende enn jeg var, men jeg setter høye krav til meg selv og er mer opptatt av de kravene jeg setter til meg selv, enn de andre setter til meg. Så det å bli lege har jeg hatt litt blandede følelser overfor. Da jeg gikk på videregående, var det det siste jeg skulle bli, men så krøp jeg til korset og ble det likevel.

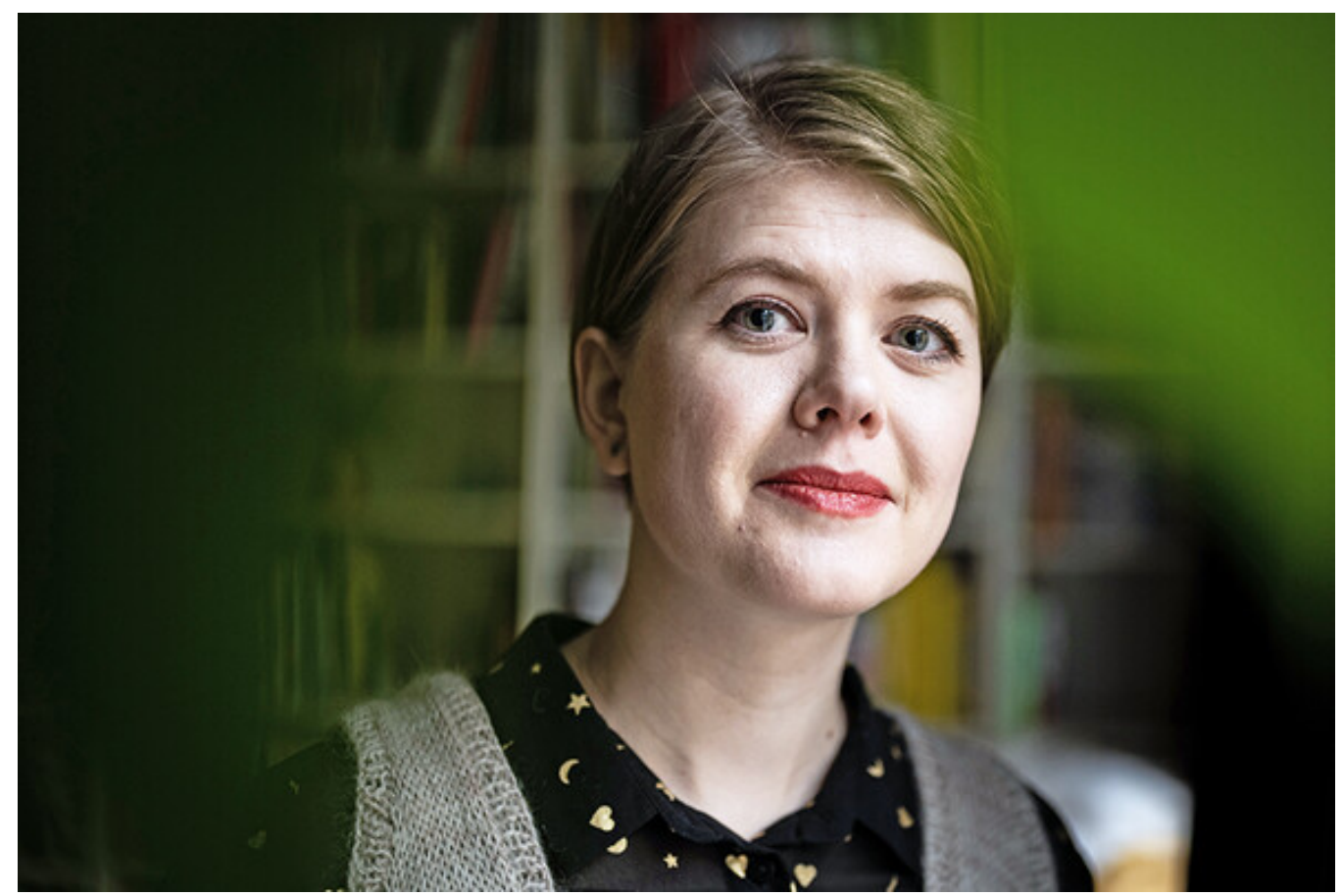

Foto: John Trygve Tollefsen

- Krøp til korset?

- Jeg ville ikke bli lege fordi alle rundt meg sa at det var det jeg burde bli med gode karakterer. Jeg liker ikke å bli fortalt hva jeg bør gjøre. De som så meg utenfra hadde nok likevel rett i at jeg passer som lege, og nå er jeg glad for det valget, medgir Støkken Dahl.

Med en mor som var kjemilærer og tok med flytende nitrogen hjem for å lage softis med barna, og en far som var geofysiker, var naturfag tross alt et nærliggende valg. I forordet til Gleden med skjeden takker hun også sin egen familie som «tålmodig har hørt på lange, og til tider ganske innbitte, monologer om hymen, vulvasmerter, herpes og annet grums».

- Det var jo først etter at jeg valgte å bli nerd på seksuell helse at det var naturlig å diskutere disse temaene med familien. Jeg tror ikke jeg diskuterte herpes og skjedekrans med noen før det var et bokprosjekt. Det er jo litt flaut, medgir hun. 
«Vi har klart å se på disse temaene med kjcerlighet, ikke bare fordi dette

er faglig spennende stoff, men også fordi det å snakke åpent om

skambelagte temaer kan hjelpe folk»

- Men den faglige konteksten gjør det interessant og naturlig å snakke om. Hvor som helst og med hvem som helst, legger hun til.

Åpenhet rundt seksualitet og helse er nå blitt en like stor selvfølge som det å reise verden rundt med medforfatter Brochmann og snakke om Gleden med skjeden.

- Vi har klart å se på disse temaene med kjærlighet, ikke bare fordi dette er faglig spennende stoff, men også fordi det å snakke åpent om skambelagte temaer kan hjelpe folk. Både Nina og jeg har hatt mange sterke møter med lesere både i Norge og utlandet hvor vi opplever at det vi har skrevet, faktisk har bidratt til mindre skam og gjort en forskjell for noen, forteller Støkken Dahl.

\section{Sammen om Underlivet}

At det skulle bli Nina Brochmann og Ellen Støkken Dahl som sammen endte med å skrive en verdenssuksess om kvinners underliv, var det likevel ingen av dem som så for seg da de begynte på medisinerstudiet i 2010. De gikk på samme kull, men hadde lite med hverandre å gjøre før de møttes i MSO (Medisinerstudentenes seksualopplysning).

- Vi var helt ukjente med hverandre før vi sammen ble satt til å skrive en veileder om seksuell helse for asylmottak, forteller Støkken Dahl om starten på det som etter hvert er blitt et nært vennskap og suksessrikt samarbeid.

Like etter tok Nettavisen kontakt og ønsket at de to skulle skrive en faglig, men lett tilgjengelig blogg om seksuell helse. Det ble i 2015 til den populære bloggen «Underlivet».

- Vi vet fortsatt ikke helt hvordan det skjedde. Hvem var det egentlig som fant på at vi skulle jobbe sammen om en blogg? Det var litt sånn Hæ? Oss to? Hvorfor? forteller hun lattermildt. Forfattermakker Nina Brochmann bekrefter hvordan de snublet inn i bokprosjektet:

- Vi følte at vi var et slags arrangert ekteskap, men som viste seg å bli svært vellykket, sier Brochmann i en kommentar til samarbeidet med Støkken Dahl.

Det var altså ingen selvfølge at de de to skulle finne hverandre, men da Aschehoug tok kontakt og boken Gleden med skjeden ble lansert to år senere, var det kø langt utenfor forlagsporten. Sjelden har en lanseringsfest for en norsk bok vært like populær. De to ble nærmest tatt imot som popstjerner. Boken er nå oversatt til 36 språk, også til arabisk. I Russland er temaet fremdeles såpass kontroversielt at boken har 18-års grense og er "plastet» slik at den ikke kan åpnes og smugleses i butikk. Russland er det største enkeltmarkedet og har der solgt i over 200 ooo eksemplarer.

\section{Punkrock og nye hårsveiser}

At de to ytre sett var motsatser til hverandre, kommer frem av beskrivelsen Brochmann har om seg selv: «en typisk Oslo Vest-jente, smilende, kjekk og grei». Mens Ellen var en som «sjelden smilte, hadde ring i nesa, drev med kampsport og spilte i punkband». Brochmann avslører at Støkken Dahl endret hårfarge fire ganger i løpet av første semester.

- Hehe ... det stemmer at jeg ofte skiftet hårsveis, innrømmer Støkken Dahl.

- Hva er det et uttrykk for? lurer vi.

Svaret kommer kontant: 
- Dårlig impulskontroll og sterk trang til å prøve noe nytt. Jeg klarer ikke alltid stoppe meg selv. Like før jeg giftet meg, klarte jeg faktisk å skinne meg. Jeg klippet av meg alt håret i et innfall, avslører Støkken Dahl og smiler igjen.

- Det ble ganske fint faktisk, men det var i den verste korona-nedstengningen så det var ikke så mange som så meg. Vi var bare fire på bryllupsfesten.

Ektemannen er profesjonell musiker, men Støkken Dahl har også sitt eget hobbyband. I ti år har hun spilt gitar og sunget i punkbandet «Gutsies». Bandet har hatt flere mindre livekonserter.

«Det å lage noe fordi det føles bra og ikke nødvendigvis fordi det skal vare objektivt bra, er befriende»

- Det er en veldig fin hobby å ha: det å lage noe sammen og ikke føle at man trenger å være flink til noe. Jeg er elendig til å spille gitar, men likevel kan jeg stille meg på en scene, synge og skrive låter. Det er veldig befriende. At det også kommer noen og hører på som sier de liker det, er jo helt topp. Det er fint å utfordre seg selv litt.

- Vi lever i en prestasjonskultur. Alt er så resultatorientert. Jeg er jo også litt farget av det. Mens det å lage noe fordi det føles bra og ikke nødvendigvis fordi det skal være objektivt bra, er befriende. Akkurat det gjelder ikke bare meg, men noe jeg tror mange hadde hatt godt av. Det å skape noe sammen med noen, jobbe kreativt med andre slik jeg også gjør med Nina, det tror jeg er en bra ting. Det gjør i hvert fall meg glad, oppsummerer trettiåringen.

\section{Syfilisasjon}

Et annet tema som gjør henne glad, er allerede nevnte favorittsykdom.

Det er på tide å samle trådene. Vi må tilbake til hvorfor bløt sjanker og en norsk lege ved navn Boeck er viktig i historien om syfilis. Og hva betyr egentlig syfilisasjon?

- Det som er så interessant, er at bløt sjanker ble brukt som behandling, forteller Støkken Dahl. Hun legger raskt til:

- Selv om det ikke virket.

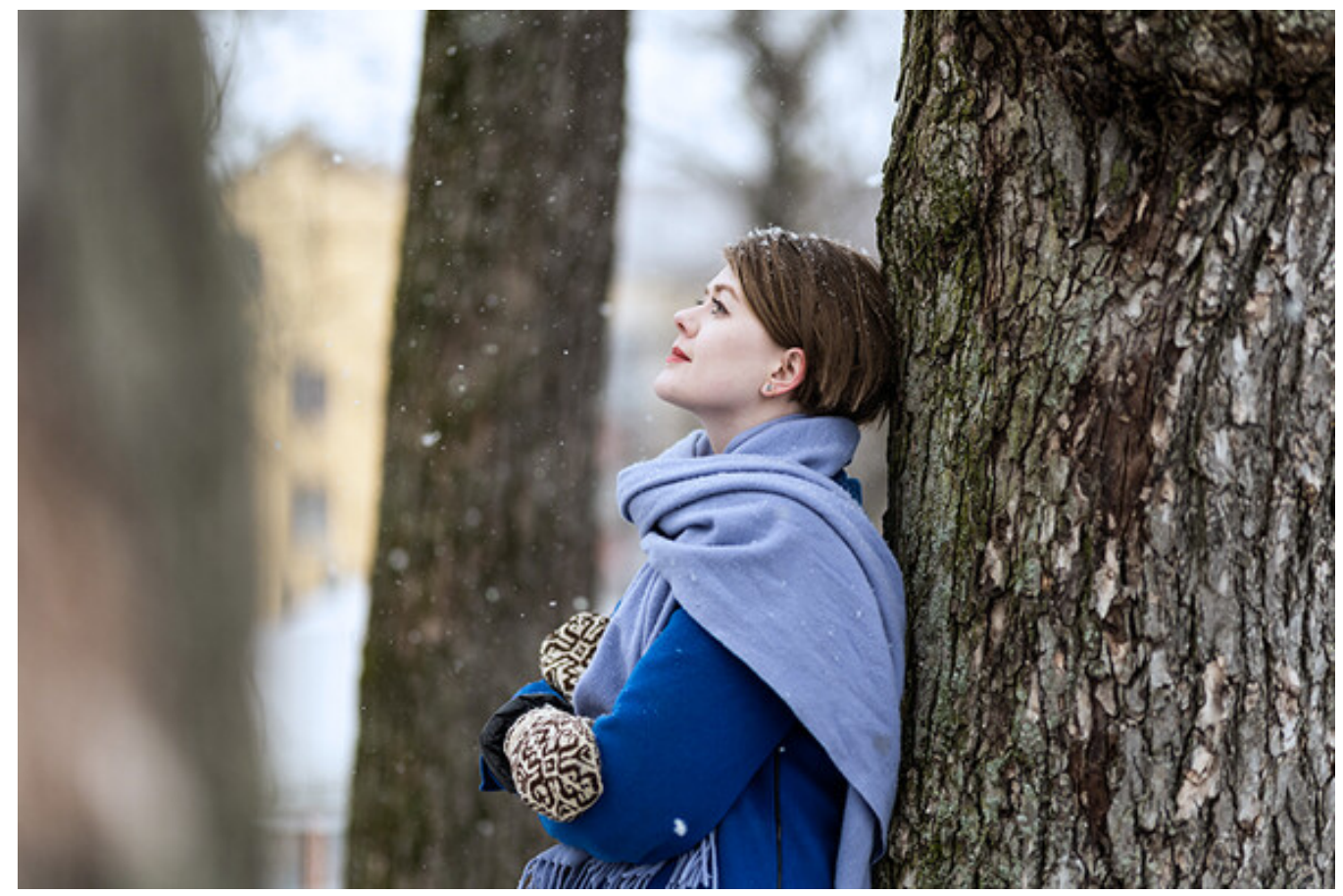


Foto: John Trygve Tollefsen

Og det er her Carl Wilhelm Boeck blir en viktig person. På midten av 18oo-tallet eksperimenterte han med puss fra bløt sjanker og inokulerte dette under huden på pasienter med syfilis. Metoden ble kalt syfilisasjon. Støkken Dahl har skrevet i detalj om dette i antologien nevnt innledningsvis.

- Når man ser på den medisinske vitenskapshistorien, snakker vi ofte om store menn og viktige oppdagelser. Flemming som oppdaget penicillinet. Jenner som begynte med vaksinasjon mot kopper. Mens alle de historiene der det gikk fullstendig på tverke, snakker man ikke om. Det som er litt sjarmerende med syfilisbehandling i Norge, er jo at Carl Wilhelm Boeck var like overbevist om at han videreutviklet en effektiv syfilisbehandling. Problemet var bare at han tok feil, forteller forfatteren.

Boecks forsøk på en immuniseringsstrategi der hard sjanker behandles med puss fra bløt sjanker, som jo er en helt annen type sykdom, var derfor nytteløs. Rundt 175 pasienter ble inkludert i forsøkene hans og utsatt for dette eksperimentet, ifølge Støkken Dahl.

- Boeck hadde like stor selvtillit som de som faktisk hadde lykkes med nye oppdagelser, og han tok også like stor risiko med pasientene selv om han altså ikke hadde samme suksess.

«Bulgakov er kjempemorsom. I tillegg viser han hvor sårbar man er som nyutdannet lege»

Hun utdyper:

- Det er spennende å gå inn i de medisinske feilene som ikke huskes. Selv om det må ha vært forferdelig for pasientene, understreker hun.

Har du skrevet setninger av typen «min personlige favoritt blant litterære syfilisfremstillinger», er det åpenbart at en fordypning i syfilis er blitt til både foredrag, artikler og snart del av en ny bok. Og for de som lurer: Ellen Støkken Dahls litterære syfilisfavoritt er novellen «Stjernedryss» av den russiske forfatterlegen Mikhail Bulgakov.

- Stjernedryss er Bulgakovs metafor for utslettet roseola, som man får i syfilis' sekundærstadium. Metaforen er treffende, utslettet ser virkelig ut som stjernedryss. Samtidig gjør han noe objektivt stygt til noe objektivt vakkert.

- Bulgakov er kjempemorsom. I tillegg viser han hvor sårbar man er som nyutdannet lege. Han jobbet som turnuslege på den russiske landsbygda på 1920-tallet. I novellene skriver han om hvordan han forsøker å virke mer erfaren ved å ta på seg briller for å se eldre ut og gjøre stemmen dypere, men så møter han utfordringer som går langt over hodet på ham. Nå ble dette et langt svar på spørsmålet ditt, avbryter Støkken Dahl seg selv, men runder av:

- I likhet med mange av oss som er vant til å være trygge på sin egen «indre flinkhet» så skriver Bulgakov om når møtet med virkeligheten blir mer utfordrende enn det man er forberedt på. Akkurat det kan jeg kjenne meg godt igjen i, oppsummerer hun.

Publisert: 28. februar 2022. Tidsskr Nor Legeforen. DOI: 10.4045/tidsskr.22.0036

(C) Tidsskrift for Den norske legeforening 2023. Lastet ned fra tidsskriftet.no 26. april 2023. 